Mo(110)表面における Ce 薄膜の 構造と成長に関する研究 ${ }^{\dagger}$

\author{
田中 泰明・亀井 雅之・後藤 芳彦 \\ 東京理科大学 基礎工学部 ⿶278 野田市山崎 2641 \\ （1996年3月 18 日受付，1996年5月 29 日掲載決定）
}

\title{
Studies on Structure and Growth of Ce Thin Films on a Mo(110) Surface
}

Yasuaki TANAKA, Masayuki KAMEI and Yoshihiko GoTOH

Department of Materials Science and Technology, Science University of Tokyo 2641, Yamazaki, Noda 278

(Received March 18, 1996: Accepted May 29, 1996)

\begin{abstract}
The surface structures and growth mode of $\mathrm{Ce}$ thin films on $\mathrm{Mo}(110)$ surface were investigated by reflection high-energy electron diffraction. Five kinds of two-dimensional superstructures of $\left(\begin{array}{ll}7 & 0 \\ 1 & 2\end{array}\right),\left(\begin{array}{cc}5 & -1 \\ 1 & 2\end{array}\right),\left(\begin{array}{ll}3 & 0 \\ 1 & 2\end{array}\right),\left(\begin{array}{cc}1 & -1 \\ 1 & 2\end{array}\right)$ and $\left(\begin{array}{cc}5 / 8 & 0 \\ 1 & 2\end{array}\right)$ and one kind of onedimensional structure were found with Ce submonolayers. All of these structures show a common periodicity of $\sqrt{2} \mathrm{a}_{0}$ Mo along $\mathrm{Mo}[\overline{1} 10]$ direction. This periodicity is considered to be very stable and dominant in case of the submonolayer coverage of $\mathrm{Ce}$ thin films on the Mo(110) surface. Cerium grows in accordance with the Stranski-Krastanov growth mode in which two Ce monolayers grow initially in the substrate temperature range from 500 to $800^{\circ} \mathrm{C}$. The Ce two-dimensional layers are composed of a distorted fcc $\gamma$ - $\mathrm{Ce}(111)$ layer and a fcc $\gamma-\mathrm{Ce}(111)$ layer for the $1 \mathrm{st}$ and the 2 nd layers, respectively. The first Ce monolayer is expanded by $7.8 \%$ in [1 $\overline{1} 0]$ direction and $5.6 \%$ in [11 $\overline{2}]$ direction compared with the fcc $\gamma-\mathrm{Ce}(111)$ layer.
\end{abstract}

\section{1. はじめに}

Ceおよびその化合物は異常に高い電子比熱係数や価 数摇動など特異的な物性を示すことが知られており注目 されている。近年ではこれらの薄膜について放射光を用 いた電子状態の测定が様々な基板との組み合わせについ て行われている( 4)。一方で, Ceやその化合物薄膜の成 長初期段階における構造に関する研究は少ない。

高融点金属である Mo，W の(110)面上に希土類元素を 1 原子層（ML）程度蒸着し, 表面の構造の変化を調べる 研究は $\mathrm{Sm}, \mathrm{Yb}, \mathrm{Gd}, \mathrm{Tb}$, 等の組み合わせで行われてい る $^{5 \sim 7}$ 。その結果 1 原子層以下の範囲では, バルクの構 造と異なる表面長周期構造が多数現われることが報告さ れている。これら希土類金属は，基板として用いた Mo やWの原子半径と比較して $1.3 \sim 1.8$ 倍程度大きな原子半

第 15 回表面科学講演大会（1995年11月 28 日～11月 30 日） にて発表
径を有している。そのため希土類金属の成長初期段階の 構造を明らかにすることは, ヘテロエピタキシャル成長 機構の起源を探る上でも非常に重要と考えられる。また 同時に表面における物性の研究への寄与も大きいと思わ れる。

ところで，MoやWといった bcc 基板上における $\mathrm{Ce} の$ 表面構造に関する研究は皆無に等しく，特にMo表面に 関する報告はなされていない ${ }^{8 \sim 10)}$ 。そこで我々は, $\mathrm{Mo}(110)$ 表面上での $\mathrm{Ce}$ 薄膜の成長初期段階について, RHEEDを用いて詳しく調べた ${ }^{11 \sim 13)}$ 。本論文では特に基 板上での被覆率が $1 \mathrm{ML}$ 程度の範囲と, 高温域における 構造と成長について述べる。

\section{2. 実 験 方 法}

実験は反射高速電子線回折（RHEED），および試料回 転用のマニピュレーターが取り付けられた, 到達真空度 $10^{-10}$ Torr の超高真空装置内で行った（ANELVA: MBE- 


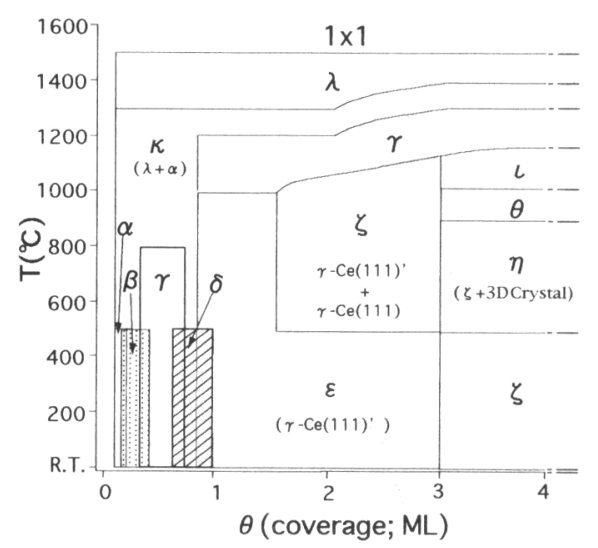

Fig. 1 The phase diagram of the surface structures of Ce adsorbed on the $\operatorname{Mo}(110)$ surface obtained by changing the initial Ce coverages and annealing temperature.
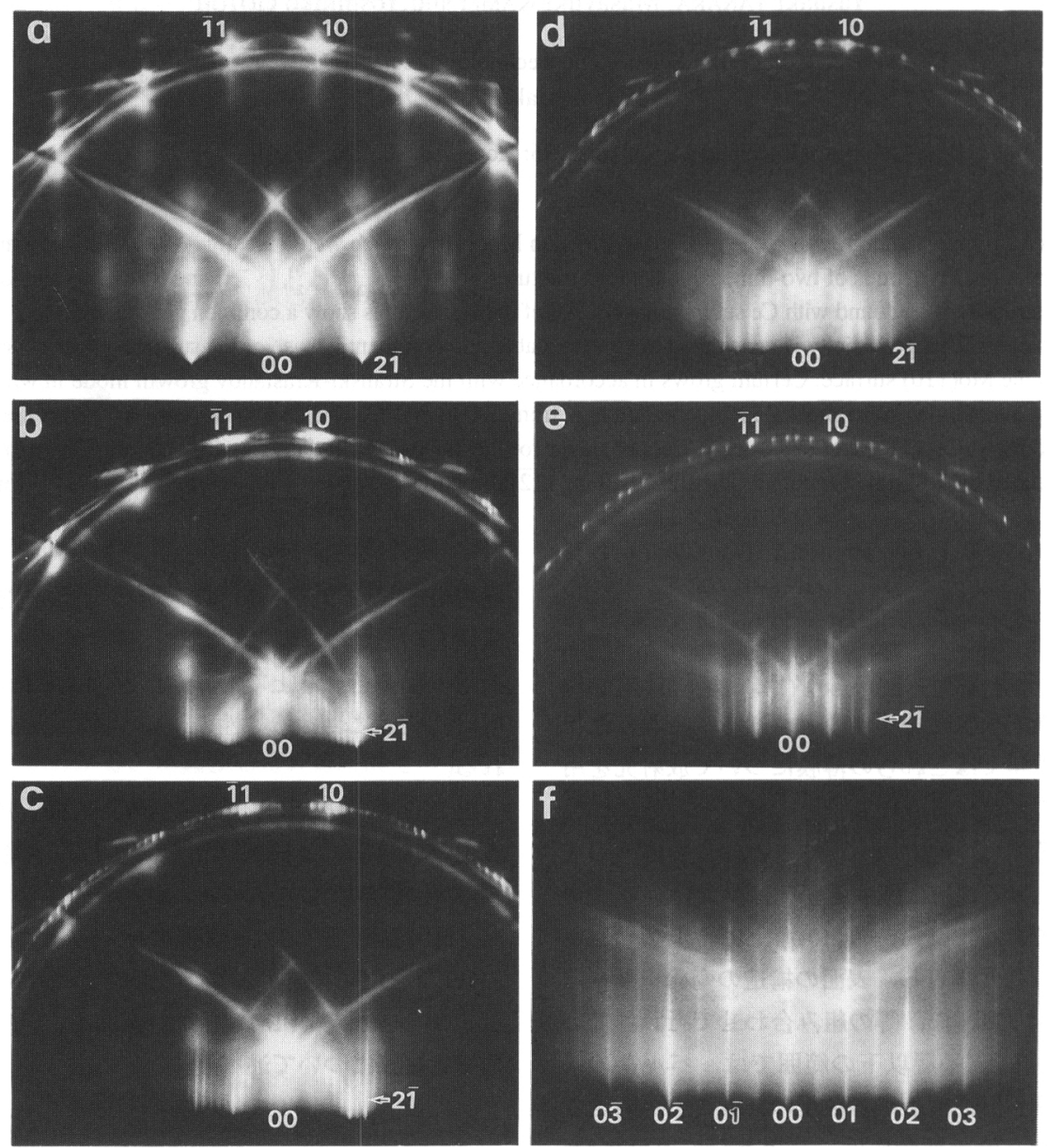

Fig. 2 The series of RHEED patterns at submonolayer coverages of Ce on Mo(110) surface. The incident beam of RHEED was parallel to the $\mathrm{Mo}[\overline{1} 10]$ and $\mathrm{Mo}[001]$ direction for (a) to (e) and (f), respectively. (a) clean Mo surface, (b)

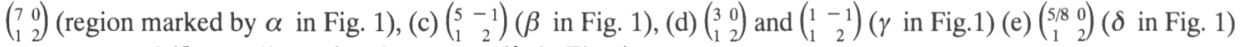
structures and (f) one-dimensional structure ( $\lambda$ in Fig. 1$)$. 
るシャープな $1 \times 1$ RHEEDパターンが観察できたときこ れを清浄表面とした ${ }^{11}$ 。

実験手順は, まず上記の方法で得られたMo清浄表面 上に基板温度が室温の状態で一定量のCeを蒸着する (0.1〜 $20 \mathrm{ML} \mathrm{;} 1 \mathrm{ML}=2.9 \AA)$ 。蒸着後, 基板を $\mathrm{Mo} の$ 清 浄表面が再び現われるまで徐々に昇温し $\left(\sim 1500^{\circ} \mathrm{C}\right)$, このときに現われる表面構造およびその変化を RHEED で観察した。

\section{3. 結果および考察}

\section{1 概説}

$1 \times 1$ 構造が観察された Mo(110)表面上にCeの量を 0.1 〜 $20 \mathrm{ML}$ ま゙変化させて蒸着し，その後徐々に基板温度 を上昇させた。両者の変化に伴い, 様々な表面構造が観 察された。

Fig. 1 は横軸に Ceの蒸着量を, 縦軸に試料温度をとっ た Mo(110)表面上における Ceの表面構造の“状態図”で ある。基板温度を一定に保ちながら Ceを蒸着させた場 合にも，Fig. 1 とほぼ同様の状態図を得ることができた。 RHEED観察はすべて試料を充分冷却して室温で行った が, 冷却中に高温域で形成された表面構造の変化は観察 されなかった。Fig. 1は観察された表面構造により $\alpha$ か ら入で表される，11種類の領域に分割されている。これ を基板上での被覆率に注目すると, 大きく2つに分けて
説明することができる。

まず表面における被覆率が 1 ML以下の場合である。 これはFig. 1 において初期蒸着量が 1 ML以下の $\alpha, \beta$, $\gamma, \delta$ のつの領域と, 蒸着量が 1 ML以上で基板温度が $900 \sim 1000^{\circ} \mathrm{C}$ 以上の および $\gamma$ さらに高温である $\kappa$ と $\lambda$ の7つの領域が該当する。後者の4つは基板上からのCe 原子の再蒸発によるものである。これらの構造の詳細に ついては 3.2 節にて述べる。

一方は表面における被覆率が 1 ML以上の場合である。 $\varepsilon, \zeta, \theta$, および $\eta$ の 4 つの領域がこれに該当し, fcc 構造の $\gamma$ - Ce の稠密面の構造に由来する単原子層が観察 される。また $\eta$ で示した領域では, 単原子層に加えて三 次元結晶が観察される。これらの構造のうち, 本論文で は $\varepsilon$ との領域について 3.3 節で述べる。

\section{2 被覆率 1 ML未満での表面構造}

Fig. 2 に基板上での被覆率が $1 \mathrm{ML}$ 末満のときの RHEED パターンの変化の様子を示した。電子線の入射 方向は（a ）から（e ）では[110]Mo方向, (f) の電子 線入射方位は[001]Mo方向である。

まずFig. 2 (a) は Mo(110)の清浄表面のRHEED パター ンである。指数付けされたストリークおよびスポットは $\mathrm{Mo}$ 基板による回折線である。この Mo 表面に室温で Ce を蒸着していくと, $0.1 \mathrm{ML}$ 至るまで清浄表面のパター ンは変化しない。これはこの蒸着量の範囲で, Ceによ

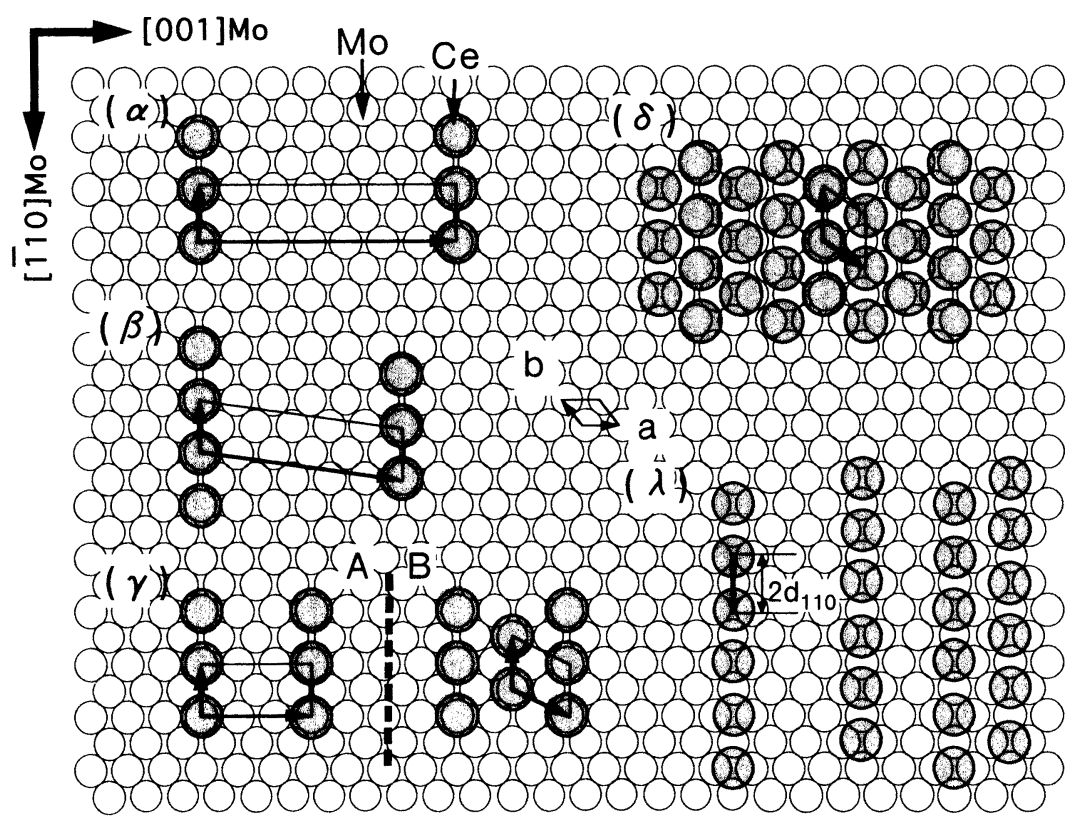

Fig. 3 The real atomic arrangement models of $(\alpha)\left(\begin{array}{ll}7 & 0 \\ 1 & 2\end{array}\right),(\beta)\left(\begin{array}{cc}5 & -1 \\ 1 & 2\end{array}\right),(\gamma)\left(\begin{array}{ll}3 & 0 \\ 1 & 2\end{array}\right)$ and $\left(\begin{array}{cc}1 & -1 \\ 1 & 2\end{array}\right),(\delta)\left(\begin{array}{cc}5 / 8 & 0 \\ 1 & 2\end{array}\right)$ and $(\lambda)$ one-dimensional structures, respectively. All of these surface structures has the periodicity of $\sqrt{2} \mathrm{a}_{0}$ Mo along $\mathrm{Mo}[\overline{1} 10]$ orientation. 
る秩序だった表面構造が形成されていないためであると 考えられる。

蒸着量が $0.1 \sim 0.2 \mathrm{ML}$ の範囲（ $\alpha$ 領域）では, Fig. 2 （b）に示すRHEEDパターンが観察された。Moによる0

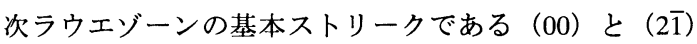
間を 14 分割するように, Ceによる13本の新しいストリ ークが出現している。しかしMoの0次と 1 次のラウエゾ ーン間には新しい回折スポットは見られない。Fig. 3 ( $\alpha$ ）に Fig. 2（b）のRHEED パターンより求めたCe 原子 の実格子空間における単位胞の配列モデルを示す。この 図において白丸はMo原子，塗りつぶした丸はCe原子を 表している。またFig. 3で $\alpha \sim \lambda$ のギリシャ文字はFig. 1 のそれに対応している。ここでMoの基本ベクトルを $\mathrm{a}=\mathrm{a}_{0}[001] \mathrm{Mo}, b=\mathrm{a}_{0} / 2$ [111] （ここで $\mathrm{a}_{0}$ は Moの格子定数） とすると, この構造はマトリックス表示で(7 $\left.\begin{array}{l}7 \\ 1\end{array}\right)$ 構造と表 すことができる。( $\left.\begin{array}{ll}7 & 0 \\ 1 & 2\end{array}\right)$ 構造は, Mo[001]方向に対して各 Ce の原子列と $14 \mathrm{Mo}$ 原子列が, また $\mathrm{Mo}[\overline{1} 10]$ 方向での各 $\mathrm{Ce}$ 原子列と $2 \mathrm{Mo}$ 原子列が一致する整合性がある。

蒸着量が $0.15 \sim 0.4 \mathrm{ML}$ の間（ $\beta$ 領域）では, Fig. 2 (c) に示すRHEEDパターンが観察された。Moによる基本ス トリークの $(00)$ と $(2 \overline{1})$ 間を 11 分割するように, 10 本のストリークが出現している。このRHEED パターン は, 蒸着量が $0.15 \sim 0.2 \mathrm{ML}$ 範囲で( $\left.\begin{array}{l}7 \\ 1\end{array}\right)$ 構造と共に観察 される。Fig. 2 (c) より得られた実格子配列をFig. $3(\beta)$ に示す。この構造はマトリックス表示を用いて $\left(\begin{array}{cc}5 & -1 \\ 1 & 2\end{array}\right)$ と 表記される。この構造はMo[001]方向に対してこの方向 での $11 \mathrm{Mo}$ 原子列目と各 $\mathrm{Ce}$ 原子列が，また $\mathrm{Mo}[\overline{1} 10]$ 方向 に対して各 Ce 原子列とこの方向への $2 \mathrm{Mo}$ 原子列目が一 致する。

蒸着量が $0.34 \sim 0.7 \mathrm{ML}$ 範囲（ $\gamma$ 領域）では, Fig. 2 (d) に示すRHEEDパターンが観察された。RHEED パ

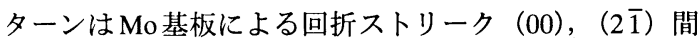
を6分割するように, Ceによる5本の新しいストリーク が出現するものへと変化している。このRHEEDパター ンは蒸着量が $0.4 \mathrm{ML}$ までは先述の $\left(\begin{array}{cc}5 & -1 \\ 1 & 2\end{array}\right)$ 構造と共存する。 Fig. 2（d）のRHEED パターンにおける強度分布は, こ の蒸着量の範囲において Fig. 3（ $\gamma$ ）に示すように2種類 のユニット A， Bから構成される領域が共存しているた めと考えられる。またこれらの構造はマトリックス表示 を用いるとそれぞれ，( $\left.\begin{array}{ll}3 & 0 \\ 1 & 2\end{array}\right)$ と( $\left.\begin{array}{cc}1 & -1 \\ 1 & 2\end{array}\right)$ 構造となる。

蒸着量 $0.6 \sim 0.8 \mathrm{ML}$ 範囲（ $\delta$ 領域）では, Fig. 2 (e) に示す RHEED パターンが観察された。このRHEED パタ 一ンは蒸着量が $0.7 \mathrm{ML}$ まで先述の $\left(\begin{array}{ll}3 & 0 \\ 1 & 2\end{array}\right)$ と $\left(\begin{array}{cc}1 & -1 \\ 1 & 2\end{array}\right)$ 構造と共 に観察される。この構造における $\mathrm{Ce}$ の実格子空間での 配列は，RHEEDパターンのストリークおよびスポット の強度を考慮に入れ, Fig. 3（ $\delta ）$ のように定めた。この
構造はマトリックス表示では( $\left.\begin{array}{cc}5 / 8 \\ 1 & 0\end{array}\right)$ 構造と表記される。こ の単位胞は単位べクトルの開き角がほぼ $120^{\circ}$ に等しい疑 似六角構造となっている。

$\mathrm{Ce}$ の初期蒸着量に関係なく試料を $1300 \sim 1400^{\circ} \mathrm{C}$ 以上 に昇温すると, Mo 基板表面からの Ce 原子の蒸発に伴い Fig. 2 （f）に示すRHEEDパターンが観察される（ $\lambda$ 領 域)。Ceによる回折線はMoの基本反射である（00）と （01）の半分の間隔を持った平行な直線群として現れて いる。これらは逆格子空間では面群として存在し “逆格 子ウォール” と呼ばれ, 蒸着物の一次元的な配列に起因 するものである。そのためエワルト球との交線であるス トリークは，基板を面内に回転しても常に観測される。 Fig. $3(\lambda)$ にこのRHEED パターンに対応するCe原子の 実格子配列モデルを示す。ここでは Ce 原子は Mol原子の ブリッジサイトに位置するとして描かれてある。Ce原 子の周期は $\mathrm{Mo}[\overline{1} 10]$ 方向にのみ存在し, その周期性は前 述の蒸着量が 1 ML以下（ $\alpha \sim \delta$ 領域）で観察された各 構造と共通するものである。

以上のことから考えると, 基板上での被覆率が $1 \mathrm{ML}$ 以下の範囲においては, Mo[110]方向にその原子列間隔 の2倍の周期をもって配列する構造を取ることが極めて 安定であるといえる。

\section{3 被覆率 1 ML 以上での表面樓造}

Fig. 1 で示した $\varepsilon$ 領域のうち, 蒸着量が $0.9 〜 1.5$ MLの 範囲の試料を徐々に昇温していくと, 室温蒸着時に観察 された RHEED パターンのバックグラウンドは徐々に減 少してゆく。

Fig. 4 （a）は蒸着量 $1 \mathrm{ML}$ の試料を, $800^{\circ} \mathrm{C}$ でアニール したときのRHEEDパターンである。電子線の入射方位 はMoの[110]方向と平行である。Moの基本ストリーク (00) と（21)）の間には，4本のストリークが等間隔をも って現れているが, “A” で示したストリークの強度が 強い。これらのストリークは, Mo基板上に成長した Ce の単原子層から生じたものと考えられる。このRHEED パターンでは Moの0次と 1 次ラウエゾーンの間に, $\mathrm{L}_{01}$ と $\mathrm{L}_{02}$ で示した新しい2本のラウエゾーンが現れている。 Fig. 4 (a) のRHEED パターンより求めた, 実格子の配 列モデルをFig. 4（b）に示す。これはバルクのfcc構造 を持つ $\gamma$ - $\mathrm{Ce}(111)$ 面を[112]方向に $5.6 \% ，[1 \overline{1} 0]$ 方向に $7.8 \%$ 引き伸ばした（“A”で示したストリークの間隔に対応） もので, 歪んだ二次元六方格子構造である。そして基板 の $\mathrm{Mo}(110)$ 面とは[11 0$] \mathrm{Ce} / /[001] \mathrm{Mo}$ の関係を持つ Nishiyama-Wassermann方位関係をとっている。またこの構造 は基板に対して， $4 \mathrm{a}+3 \mathrm{~b}$ と一 $\mathrm{a}+3 \mathrm{~b}$ を基本ベクトルに 持つ長周期の整合性を持っている（図中の大きなひし 形)。これはMoの[001]方向に対してMoの5 原子列目と 


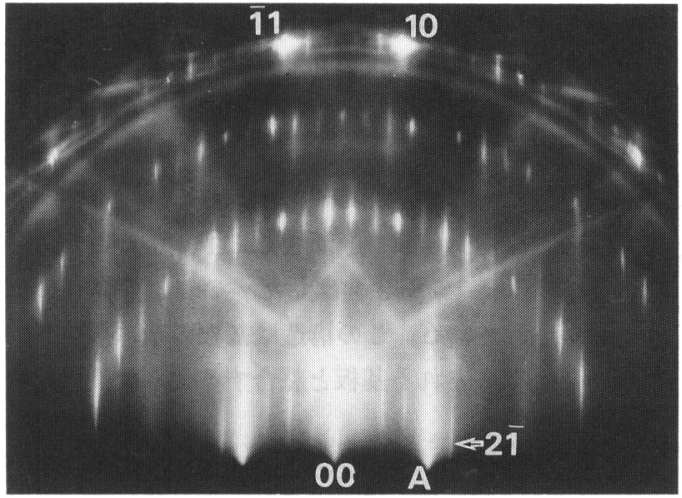

(a)

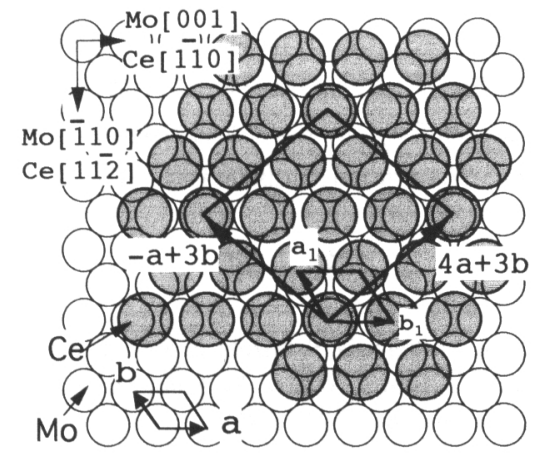

(b)

Fig. 4 (a) A RHEED pattern observed in the region marked by $\varepsilon$ in Fig.1 ( $\gamma$-Ce(111)' layer). The incident beam was parallel to the $\mathrm{Mo}[\overline{1} 10]$ direction. The streak marked by "A" corresponds to the 1st Ce layer. (b) Real atomic model of $\gamma$-Ce(111)' layer. Open and filed circles denote Mo atoms and $\mathrm{Ce}$ atoms, respectively. The unit vectors of Ce layer is indicated by $a_{1}$ and $b_{1}$. Large coincident unit of $\left(\begin{array}{cc}4 & 3 \\ -1 & 3\end{array}\right)$ structure is shown with large parallelogram.

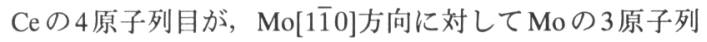
目と Ce の 2 原子列目が一致しており, 内部に 8 個のCe 原 子を含んでいる大きなユニットである。この構造の原子 密度を計算すると $7.77 \times 10^{14}$ 個 $/ \mathrm{cm}^{2}$ となり，0.896 MLに 相当する。この長周期構造はマトリックス表示を用いる と $\left(\begin{array}{cc}4 & 3 \\ -1 & 3\end{array}\right)$ 構造となる。本論文ではこのように $\gamma-\mathrm{Ce}(111)$ か ら引き伸ばされた構造を, 以下 $\gamma-\mathrm{Ce}(111)$ ' 構造と呼ぶこ とにする。このように稠密面の構造が大きく引き伸ばさ れる理由としては, 基板との整合性を保つことにより表 面エネルギーが低くなるためであると考えられる。

Fig. 1 の $\varepsilon$ 領域のうち蒸着量が $1.5 \sim 2.5 \mathrm{ML}$ の範囲の試 料を徐々に昇温していくと, RHEED パターンは $500^{\circ} \mathrm{C}$ ま ではほとんど変化が見られない。しかし $500 〜 1100^{\circ} \mathrm{C} の$ 温度範囲で $\zeta$ 領域が現れる。Fig. 5（a）はMo(110)基板 上に室温で Ceを $1.5 \mathrm{M} \mathrm{L}$ 蒸着後, $800^{\circ} \mathrm{C}$ でアニールした

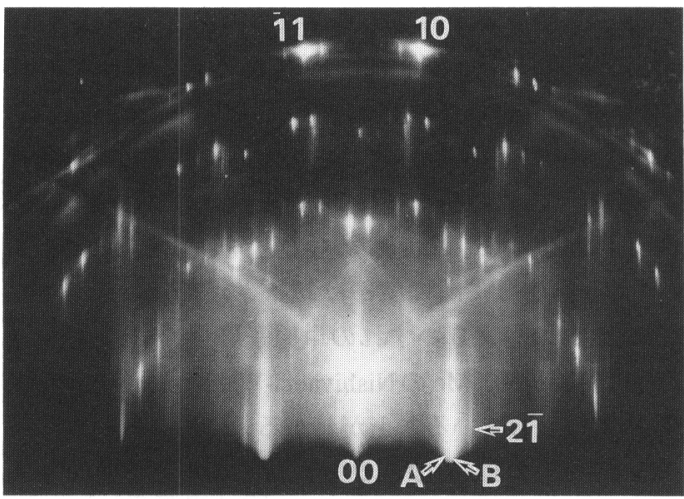

(a)

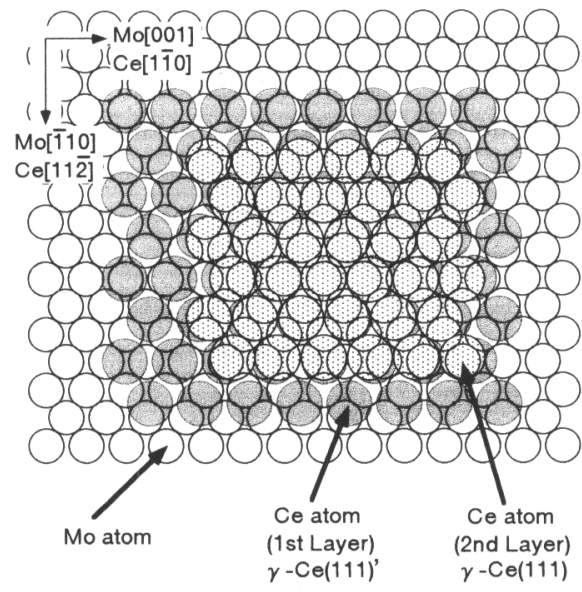

(b)

Fig. 5 (a) A RHEED pattern observed in the region marked by $\zeta$ in Fig. 1 ( $\gamma-\mathrm{Ce}(111)$ ' and $\gamma-\mathrm{Ce}(111)$ layer). The incident beam was parallel to the $\mathrm{Mo}[\overline{1} 10]$ direction. New streak marked by "B" appears adjacent to that of " $A$ ". Note that the spacing of streak marked by " $A$ " is not changed. (b) Real atomic model corresponding to RHEED pattern. Open and filled circles denote Mo and $\mathrm{Ce}$ atoms of $\gamma-\mathrm{Ce}(111)$ ' layer(1st layer), respectively. Hatched circles denote those of $\gamma$-Ce(111) layer (2nd layer).

後のRHEED パターンである。電子線の入射方位は [110]Mo と平行である。このパターンの特徴は, Fig. 4 (a) で示した $\gamma-\mathrm{Ce}(111)$ ’ 構造の回折パターン (“A” で示 したストリーク）に加えてそのすぐ外側に, “B”で示し た新しいストリークが現れていることである。蒸着量を 増加しても 0 次のラウエゾーンで引き続きシャープなス トリークが観察されるため, 試料表面で広範囲にわたる 単原子層が形成されていると考えられる。そして“B” で示されたストリークの位置は, バルクの $\gamma-\mathrm{Ce}(111) の$ [112]方向の原子列の間隔と対応するものであった。 
以上の実験事実よりこの蒸着量の範囲では $\gamma-\mathrm{Ce}(111)$, 構造をとる第一原子層上に, fccである $\gamma-\mathrm{Ce}(111)$ の構造 を持つ単原子層が形成されているものと考えられる。 Fig. 5 （b）にFig. 5（a）より求めた, 実格子における原 子配列を示す。この図の中で Mo 基板および Ce 第 1 層目 の原子はFig. 4 (b) で示したものと同じである。そして Ceによる第 2 原子層の原子は網掛された丸で示してあ る。またこの図よりいずれの単原子層も，Mo基板に対 して[1̄0]Ce//[001]Moの Nishiyama-Wassermann方位関係 を取って成長していることがわかる。

Fig. 5 (a) のRHEED パターンはこの温度範囲でさら に蒸着量を増加させた場合においても基本的には変化し なかった。しかし蒸着量が 3 ML以上の試料を系外に取 り出しその表面をSEM 観察したところ, 直径 $1 \mu$ 程度の Ceによると考えられる微結晶が確認された。よって， 基板温度が $500 \sim 800^{\circ} \mathrm{C}$ 範囲では Ce は初期に 2 層から なる単原子層を形成する Stranski-Krastanov（S-K）様式 で成長すると結論することができる。S-K成長は高温で の金属/金属や金属/半導体の系において一般的に観察さ れる。しかし本研究で示したように初期に2層の単原子 層を含む例はこれまでにあまり報告されておらず，特異 的なものといえる。

\section{4. ま と め}

本研究ではこれまでに行われていない, Mo(110)表面 上に蒸着された Ceの表面構造および, 成長様式を反射 高速電子線回折法を用いて調べた結果について報告し た。また初期蒸着量と基板温度を変化させ現われた表面 構造をまとめた表面構造の “状態図”を作成した。この ような研究の結果から, 以下のことが明らかにされた。

1）基板上での被覆率が $1 \mathrm{ML}$ 以下の範囲では, Ceの蒸 着量の増加に伴い蒸着量の低い方から $\left(\begin{array}{ll}7 & 0 \\ 1 & 2\end{array}\right),\left(\begin{array}{cc}5 & -1 \\ 1 & 2\end{array}\right)$, $\left(\begin{array}{ll}3 & 0 \\ 1 & 2\end{array}\right),\left(\begin{array}{cc}1 & -1 \\ 1 & 2\end{array}\right)$ および $\left(\begin{array}{cc}5 / 8 & 0 \\ 1 & 2\end{array}\right)$ の 種類の表面長周期構造が観 察された。

2）蒸着量に関係なく基板温度が $1300^{\circ} \mathrm{C}$ 以上になると, $\mathrm{Mo}[\overline{1} 10]$ 方向にのみ周期性を持つ一次元周期構造が現 れた。

3）表面長周期構造，一次元周期構造はいずれも,
$\mathrm{Mo}[\overline{1} 10]$ 方向にその原子列間隔に対して 2 倍の周期を含 んでいた。このことは，基板上の被覆率が 1 ML以下 のときにこの周期性が，きわめて高い安定性を持つこ とを示している。

4) 蒸着量が $1 \mathrm{ML}$ 付近の試料を昇温すると，500〜800 ${ }^{\circ} \mathrm{C}$ の温度範囲で $\gamma$ - $\mathrm{Ce}(111)$ 面を $\mathrm{Ce}[1 \overline{1} 0]$ 方向に $7.8 \%$, $\mathrm{Ce}[11 \overline{2}]$ 方向に $5.7 \%$ 引き伸ばした $\gamma-\mathrm{Ce}(111)$ '構造の単 原子層が形成される。この構造は基板の基本ベクトル を用い( $\left.\begin{array}{cc}4 & 3 \\ -1 & 3\end{array}\right)$ で表される基板と整合するような長周期構 造を含んでいる。

5）基板温度が $500 \sim 800^{\circ} \mathrm{C}$ の高温域で $\mathrm{Ce}$ 薄膜は，第 2 原子層まで層成長する Stranski-Krastanov成長様式をと る。その成長過程は第一原子層に $\gamma-\operatorname{Ce}(111)$ ' 構造, 第 二原子層として $\gamma$ - Ce(111)構造が成長する。Ceによる 三次元微結晶はこれらの原子層上に形成される。単原 子層と微結晶のエピタキシャル方位関係は，いずれも Nishiyama-Wassermann方位関係を取っていた。

\section{文 献}

1) T. Okane, M. Yamada, S. Suzuki, S. Sato, T. Kinoshita, A. Kakizaki, T. Ishii, J. Yuhara, M. Katoh and K. Morita : J. Phys. Soc. Jpn. 64, 1673 (1995).

2) A. Fujimori, M. Grioni, J. J. Joyce and J. H. Weaver : Phys. Rev. B36, 1075 (1987).

3) J. Tang and J. M. Lawrence and J. C. Hemminger : Phys. Rev. B48, 15342 (1993).

4) F. U. Hillebrecht : Appl. Phys. Lett. 55, 277 (1989).

5) J. Kolaczkiewicz and E. Bauer : Surf. Sci. 175, 487 (1986)

6) A. Stenborg and E. Bauer : Surf. Sci. 185, 394 (1987).

7) A. Stenborg and E. Bauer : Phys. Rev. B36, 5840 (1987).

8) H. Homma, Kai-Y. Yang and I. K. Schuller : Phys. Rev. B36, 9435 (1987).

9) B. Kierren, T. Gourieux, F. Bertran and G. Krill : Phys. Rev. B49, 1976 (1994).

10) C. Gu, X.Wu, C. G. Olson and D. W. Lynch : Phys. Rev. Lett. 67, 1622 (1991).

11) Y. Tanaka, M. Kamei and Y. Gotoh : Surf. Sci. 365, 13 (1995).

12) Y. Tanaka, M. Kamei and Y. Gotoh : Jpn. J. Appl. Phys. 34, 5774 (1995).

13) Y. Tanaka, M. Kamei and Y. Gotoh : Surf. Sci. 掲載予定 